\title{
Evaluation of Hormone Levels in Adult Patients of Acne Vulgaris
}

\author{
Ranju Choudhary ${ }^{1}$, Ravikant Nirankari² \\ 1,2 Department of Dermatology, SMMHMC, Saharanpur, Uttar Pradesh, India.
}

\section{ABSTRACT}

\section{BACKGROUND}

There are certain hormones which have direct effect on the sebaceous glands in both the sexes, as excess sebum production is a prerequisite for the development of the acne. Hence this research article about the hormonal profile in adult patients of acne vulgaris. Hormonal parameters which includes androgens, growth hormone, insulin \& insulin like growth factors, glucocorticoids, and ACTH.

\section{METHODS}

Selection criteria were the patients attending OPD in the Department of Skin and V.D. in our medical college. Patients within the age group of 12 to 45 years in both the sexes with acne vulgaris of grade 1 to grade 4 were included in this study. A randomized control study for a period of one year among 75 newly diagnosed patients were taken as cases and there were 75 patients in the control group who were free from acne.

\section{RESULTS}

Total $6 \%$ of males and $26.6 \%$ female patients had increased levels of testosterone. $39.2 \%$ and $20 \%$ of male and female patients had increased levels of DHEA-S respectively. Normal levels of growth hormone were found in both the groups of cases and controls. $6.6 \%$ of female patients had increased levels of insulin.

\section{CONCLUSIONS}

This study concluded that patients with severe acne, acne distributed along the jaw lines, recalcitrant acne not responding to conventional therapy and having other features of hyperandrogenism should be evaluated for the above-mentioned hormones to rule out the underlying hormonal abnormality leading to acne vulgaris.

\section{KEY WORDS}

Acne, Androgens, Growth Hormone, Glucocorticoids, Insulin, Insulin Like Growth Factor.
Corresponding Author: Dr. Ranju Choudhary, House No. 6501, M.J.F. Marg, New Naveen Nagar, Saharanpur - 247001 Uttar Pradesh, India.

E-mail: ranju.choudhary82@gmail.com

DOI: $10.14260 /$ jemds $/ 2022 / 76$

How to Cite This Article:

Choudhary R, Nirankari R. Evaluation of hormone levels in adult patients of acne vulgaris. $J$ Evolution Med Dent Sci 2022;11(03):396-400, 10.14260/jemds/2022/76

Submission 09-01-2022,

Peer Review 05-02-2022,

Acceptance 11-02-2022,

Published 14-02-2022.

Copyright (c) 2022 Ranju Choudhary et al. This is an open access article distributed under Creative Commons Attribution License [Attribution 4.0 International (CC BY 4.0)] 


\section{BACKGROUND}

Acne vulgaris, is a very common malady of adolescents, is well-known and easily recognized. Acne vulgaris is a nearly universal skin disease afflicting $79-95 \%$ of the adolescent population. $1,2,3,4,5,6,7,8$ During adolescence, acne vulgaris is more common in males than in females. In adulthood, acne vulgaris is more common in women than in men. ${ }^{9}$ Acne is probably a genetic disease representing an exaggerated response of the pilosebaceous unit to normal levels of circulating androgens $\mathrm{s}^{10,11,12}$ Acne is one of the most common chronic skin disorders and is a disease of the pilosebaceous follicle. It is attributed to multiple factors, but mainly with increased sebum production. ${ }^{13}$

There are certain hormones which affects the sebaceous gland hence contributing to the acne:

a. Androgens: Sebaceous glands require androgenic stimulation to produce significant quantities of sebum. Individuals with genetic deficiency of androgen receptors (complete androgen insensitivity) have no detectable sebum secretion and do not develop acne. ${ }^{13,14}$

b. Oestrogens and sebum production: The major active oestrogen is oestradiol, produced from testosterone by the action of aromatase enzyme. Oestradiol can be converted to the less potent oestrogen, estrone by the action of $17 \beta-H S D$ enzyme. Both aromatase and $17 \beta$-HSD are present in the skin. ${ }^{15}$

c. Progesterone: Progesterone has been blamed for fluctuation of sebum levels in women during the menstrual cycle and in turn for premenstrual flare, but this has not been proved experimentally. It has no effect on the sebaceous glands in physiological doses in both sexes. ${ }^{16}$

d. Thyroid hormone: It is likely that thyroid auto-immunity might be more frequent in the adult acne patients and this should be kept in mind when screening women with the post adolescent acne, according to study by Vergou et al. ${ }^{18}$ thyroid ultrasound findings. ${ }^{17}$

e. Growth hormone (GH) is secreted by the pituitary gland. It acts on the liver and peripheral tissues to stimulate the production of insulin like growth factor (IGFs) formerly known as somatomedins. ${ }^{14}$

f. Insulin and insulin like growth factor: Growth hormone and IGF-1 play an important role for epidermal homeostasis. GH is secreted by the anterior pituitary and binds to GH-receptor (GHR), expressed on most peripheral cells of the body. ${ }^{18}$

\section{METHODS}

This prospective study was done over a period of 1 year in the Department of Dermatology in Rajendra Institute of Medical Sciences, Ranchi, India. This study was undertaken after obtaining ethical clearance and informed consent from all participants. Patients were selected based on certain inclusion and exclusion criteria.

\section{Inclusion Criteria}

1. Age-Patients in the age group of 12 to 45 years.
2. Sex-Both sexes.

3. Patients fulfilling the following diagnostic criteria i.e., patients of acne vulgaris from grade 1 to grade 4 .

\section{Exclusion Criteria}

1. Pregnant and lactating women.

2. Patient who had already taken any hormonal therapy.

3. Patient suffering from any underlying malignancy.

4. Patient having any pituitary tumours.

5. Any other systemic illness.

\section{Clinical Diagnosis of Acne Vulgaris}

The following will be used to diagnose acne vulgaris: 1) Polymorphic lesions characterized by 2) Comedones 3) Papules or pustules or nodular lesions seen on the sebaceousrich body regions, mainly the face, mid chest, back, shoulders and upper arms. Severity of acne can be graded on the clinical grounds as under:19 Grade1 (mild):comedones occasionally papules. Grade 2 (moderate): comedones, mainly papules and few pustules. Grade 3 (severe): predominately pustules, papules and nodules. Grade 4 (fulminant): mainly nodules or nodulocystic. 150 patients were included of whom 75 newly diagnosed patients were in the age group of 12-45 years and had grade 1 to grade 4 acne. They were 75 patients in the control group who were free from acne. Informed written consent was obtained for the participation in the study. Patients with severe grades of acne vulgaris, acne distributed along the jaw lines, recalcitrant acne not responding to conventional therapy or having other features of hyperandrogenism such as hirsutism were advised following investigations. Apart from the normal routine investigations hormonal profile was done. Hormonal parameters which include a) androgen, b) growth hormones, c) insulin \& insulin like growth factors, d) glucocorticoids, sample collection for serum testosterone and DHEA- venous blood samples were collected for the assay of serum testosterone \& DHEA-S. For testosterone assay three sample were collected at 20 minutes intervals and pooled together. Immediately after collection the red cells were separated and the sera was stored at $-20^{\circ} \mathrm{C}$ till assay. In females, the samples were collected only in the first half of the follicular phase of menstrual cycle. All hormones were measured by radioimmunoassay using standard techniques with commercially obtained kits.

Hormonal parameters normal levels:

Testosterone Free (in females) 0.95-4.3ng/dl

Total 20-80ng/dl

Free (in Males) 9-30ng/dl

For DHEA-S, the normal reference values are as follows:

\begin{tabular}{|ccc|}
\hline Age (years) & Females $(\mathbf{m c g} / \mathbf{d L})$ & Males $(\mathbf{m c g} / \mathbf{d L})$ \\
$12-15$ & $44-332$ & $29-412$ \\
$18-29$ & $44-332$ & $89-457$ \\
$30-39$ & $31-228$ & $89-457$ \\
$40-49$ & $18-244$ & $48-244$ \\
\hline
\end{tabular}

Growth hormones (GH): GH stimulation and suppression test are most often used to diagnose GH abnormalities. Since growth hormone is released by the pituitary gland in bursts throughout the day, random measurements of growth hormone levels are not usually clinically useful. After fasting for 10 to 12 hours, a blood sample is drawn from a vein in the arm. Then, under medical supervision, a person is given 
either a solution to drink or an intravenous (IV) solution through a vein in the arm. Blood samples are then withdrawn from veins.

Hormonal parameters normal levels:

Females $1-16 \mathrm{ng} / \mathrm{ml}$

Males $1-9 \mathrm{ng} / \mathrm{ml}$

Insulin: -After 8 hours of fasting a blood sample is obtained by inserting a needle into a vein in the arm.

Hormonal parameters normal levels:

Insulin $<12 \mathrm{mu} / \mathrm{L}(<30 \mathrm{mIU} / \mathrm{ml})$

Insulin like growth factor-1: -Insulin like growth factor-1 (IGF-1) test is an indirect measure of the average amount of growth hormone $(\mathrm{GH})$ being produced by the body. A random blood or fasting after 12 hours is required; a blood sample is obtained by inserting a needle into a vein in the arm.

\section{Reference Values}

\begin{tabular}{|cc|}
\hline Age & $\mathbf{n g} / \mathbf{m L}$ \\
12-15 years & $114-618$ \\
16 years & $115-598$ \\
17 years & $113-566$ \\
18 years & $109-527$ \\
19 years & $104-484$ \\
20 years $21-25$ years & $98-443$ \\
26-30 years & $83-344$ \\
31-35 years & $75-275$ \\
36-40 years & $71-241$ \\
41-45 years & $69-226$ \\
\hline \multicolumn{2}{c}{} \\
\hline
\end{tabular}

\begin{tabular}{|cc|}
\hline Age & $\mathbf{n g} / \mathbf{m L}$ \\
12-15 years & $134-631$ \\
16 years & $130-595$ \\
17 years & $123-546$ \\
18 years & $114-493$ \\
19 years & $105-441$ \\
20 years & $97-398$ \\
21-25 years & $84-323$ \\
26-30 years & $77-271$ \\
31-35 years & $73-244$ \\
36-40 years & $68-225$ \\
41-45 years & $62-205$ \\
\hline
\end{tabular}

Glucocorticoids: Overnight fasting blood sample taken in the morning usually at 8 a.m. from the vein of the arm. Normal level: 6- $23 \mathrm{mcg} / \mathrm{dL}$ (at 8a.m)

\section{Statistical Analysis}

Data was entered in Microsoft Excel software, and analysed using STATA software version 12 and analysed. Independent $t$ test was was used to compare the mean and to find out the significance of difference. A "p" value of $<0.05$ was considered significant.

\section{RESULTS}

Out of 75 cases there were 2 drop outs. Acne accounted for $7.5 \%$ of the total patients attending OPD in the present study. Maximum no of patients belonged to the age group of 12-20 years with 47 patients (64.3\%), followed by 21-30 years with 18 patients $(25 \%)$, the third common group affected were above 30 years with $8(10.9 \%)$ patients.

Among 73 patients, 28 (38.3\%) were males and 45 $(61.6 \%)$ were females. $14.6 \%$ and $26.6 \%$ of male and female patients had increased level of testosterone levels respectively. Mean value of testosterone were $(12.2 \pm 11.5$ vs $8.7 \pm 8.5$ ) in cases and control respectively. $39.2 \%$ and $20 \%$ of male and female patients had increased level of DHEA-S respectively. Mean value of DHEA-S were $(259.79 \pm 151.4$ vs $211.26 \pm 64.5$ ) in cases and controls respectively. Testosterone level and DHEA-S and its association with acne was significantly different from control. $(\mathrm{p}<.005)$. Table 1

Normal levels of growth hormone was found in both the cases and controls with the mean value of $(5.37 \pm 1.96$ vs 4.90 \pm 1.11 ) in cases and controls respectively. Table 2

$6.6 \%$ of female patients had increased level of insulin levels with the mean value of $(6.5 \pm 2.6$ vs $5.5 \pm .98)$ in cases and controls respectively. Table 3

Normal levels of insulin like growth factors were found in both the groups with the mean value of $(258.64 \pm 106.65$ vs $231.15 \pm 102.3$ ) in cases and controls respectively. Table 4

Normal levels of glucocorticoid were found in both the groups with the mean value of $(13.1013 \pm 4.24$ vs $12.99 \pm$ 4.05 ) in cases and controls groups. Table 5.

\begin{tabular}{|cccc|}
\hline Androgen Level & Control n=73 & Acne Patients n=73 & $\mathbf{P}$ \\
$\begin{array}{c}\text { Testosterone (ng/dL) } \\
\text { Dehydroepiandrosterone } \\
\text { sulphate(mcg/dL) (DHEA-S) }\end{array}$ & $211.26 \pm 8.5$ & $12.0 \pm 11.15$ & $\mathrm{P}=0.04$ \\
\hline Table 1. Serum Androgen Levels (Mean \pm S.D) of Patients with Acne in \\
Age Matched Acne Free Healthy Individuals \\
\hline
\end{tabular}

Independent $\mathrm{t}$ - test was applied, there was significant statistical difference between the cases and the controls group.

\begin{tabular}{|cccc|}
\hline $\begin{array}{c}\text { Hormone } \\
\begin{array}{c}\text { Growth hormone } \\
(\mathrm{ng} / \mathrm{mL})\end{array}\end{array}$ & Control $\mathbf{n = 7 3}$ & Acne Patients $\mathbf{n = 7 3}$ & P Value \\
\hline Table 2. Serum Growth Hormone Levels (Mean \pm S.D) of Patients with \\
Acne in Age Matched Acne Free Healthy Individuals
\end{tabular}

Independent $\mathrm{t}$ - test was applied, there was no significant statistical difference between the cases and the controls group.

\begin{tabular}{|cccc|}
\hline Hormone & Control $\mathbf{n = 7 3}$ & Acne Patients $\mathbf{n = 7 3}$ & P Value \\
Insulin $(<12 \mathrm{mu} / \mathrm{L})$ & $5.5 \pm .98$ & $6.5 \pm 2.6$ & $\mathrm{P}=.0021$ \\
\hline Table 3. Serum Insulin Levels (Mean \pm S.D) of Patients with Acne in Age \\
\multicolumn{4}{|c|}{ Matched Acne Free Healthy Individuals } \\
\hline
\end{tabular}

Independent $\mathrm{t}$ - test was applied, there was significant statistical difference between the case and the control groups.

\begin{tabular}{|cccc|}
\hline $\begin{array}{c}\text { Hormone } \\
\text { Insulin like growth } \\
\text { factor }(\mathrm{ng} / \mathrm{mL})\end{array}$ & Control n=73 & Acne Patients n=73 & P Value \\
\hline $\begin{array}{l}\text { Table 4. Serum Insulin Like Growth Factors Levels (Mean } \pm \text { S.D) of } \\
\text { Patients with Acne in Age Matched Acne Free Healthy Individuals }\end{array}$ \\
\hline
\end{tabular}

Independent $\mathrm{t}$ - test was applied there was no significant statistical difference between the case and the control groups.

\begin{tabular}{|cccc|}
\hline Hormone & Control $\mathbf{n = 7 3}$ & Acne Patients $\mathbf{n = 7 3}$ & P Value \\
\hline Glucocorticoid (mcg/dL) & $12.99 \pm 4.05$ & $13.013 \pm 4.24$ & 0.97 \\
\hline \multicolumn{3}{|c|}{ Table 5. Serum Glucocorticoid Levels (Mean \pm S.D) of Patients with } \\
Acne in Age Matched Acne Free Healthy Individuals \\
\hline
\end{tabular}

Independent $\mathrm{t}$ - test was applied, there was no significant statistical difference between the case and the control groups. 


\section{DISCUSSION}

Total number of patients included in the study were 150 . There were 4 drop outs 2 from case and 2 from the control groups. Androgen level: Among the 73 acne patients, increased level of testosterone was observed in Group 1 when compared to Group $2(12.0 \pm 11.15$ vs. $8.7 \pm 8.5)$ with the p-value of 0.04 . Serum dehydroepiandrosterone sulphate was observed to be increased in Group 1 when compared to Group 2(259 \pm 151.4 vs. $211.26 \pm 64.5)$ with the p-value of 0.012 (Table No. 1) Independent t- test was applied; there was statistical difference between the case and the control groups. Marynick et al. ${ }^{20}$ have reported elevated levels of DHEA-S in men with cystic acne in 1983. Hatwal et al.21 in 1990 have reported males with acne, the mean serum testosterone levels were only marginally elevated but DHEA$S$ levels were significantly higher than in controls and serum level of both the testosterone and DHEA-S were significantly higher than in controls.

\begin{tabular}{|cccc|ccc|}
\hline & \multicolumn{3}{c}{ Hatwal et al. } & \multicolumn{3}{c|}{ Present Study } \\
& $\begin{array}{c}\text { Controls } \\
\mathbf{n = 5 0}\end{array}$ & $\begin{array}{c}\text { Acne } \\
\text { Patients } \\
\mathbf{n = 5 0}\end{array}$ & $\begin{array}{c}\text { P- } \\
\text { Value }\end{array}$ & $\begin{array}{c}\text { Controls } \\
\mathbf{n = 7 3}\end{array}$ & $\begin{array}{c}\text { Acne } \\
\text { Patients } \\
\mathbf{n = 5 0}\end{array}$ & $\begin{array}{c}\text { P- } \\
\text { Value }\end{array}$ \\
$\begin{array}{c}\text { Testosterone } \\
\text { nmol/l }\end{array}$ & $22.9 \pm 5.2$ & $23.6 \pm 7.6$ & $<0.001$ & $8.7 \pm 8.5$ & $12.0 \pm 11.5$ & 0.04 \\
$\begin{array}{c}\text { DHEA-S } \\
\mu \mathrm{mol} / \mathrm{l}\end{array}$ & $3.8 \pm 1.3$ & $7.9 \pm 2.2$ & $<0.001$ & $211.26 \pm 64.5$ & $259.79 \pm 151.4$ & 0.012 \\
\hline
\end{tabular}

This study is consistent with the study done by Hatwal et al. in 1990. Hence the androgens are involved in the pathogenesis of acne vulgaris.

Growth hormones: -Among the 73 acne patients, level of growth hormone was comparable in Group 1 and Group 2 ( $5.37 \pm 1.96$ vs. $4.90 \pm 1.11$ ) with the p-value of 0.079 (Table No.2) Independent t-test was applied and there was no significant statistical difference between the cases and the controls.

Till now few studies regarding the correlation of growth hormone and acne have been yet done.

Insulin: -Among the 73 acne patients, increased level of insulin was observed in Group 1 when compared to Group 2 $(6.5 \pm 2.6$ vs. $5.5 \pm 0.98)$ with the p- value of 0.0021 . (Table No. 3)

Independent t-test was applied and there was significant statistical difference between the cases and the controls.

A randomized controlled trial comparing a diet with low glycaemic load to the high glycaemic diet demonstrated greater improvement of acne and insulin sensitivity in patients who followed low glycaemic load diet compared with the conventional high glycaemic diet. ${ }^{22}$ Another study in 2008 demonstrated that low glycaemic load decreases total lesion counts, decreases follicular sebum out flow, and changes the composition of skin surface triglycerides, ${ }^{23}$ further supporting the causal link between insulin and acne.

But there is no study indicating direct correlation between insulin levels in patients with acne vulgaris.

Insulin like growth factors: Among the 73 acne patients, level of insulin like growth factors was comparable in Group 1 and Group $2(258.64 \pm 106.65$ vs. $231.15 \pm 102.3)$ with the p- value of 0.115 (Table No. 4)

Independent t-test was applied and there was no significant statistical difference between the cases and the controls. No study regarding the correlation of insulin like growth factors level and acne has been conducted till date.

Glucocorticoids: Among the 73 acne patients, level of glucocorticoids was comparable in Group 1 and Group 2 $(258.64 \pm 106.65$ vs. $231.15 \pm 102.3)$ with the $p$ - value of 0.115. (Table No. 5)

Independent t-test was applied and there was no significant statistical difference between the cases and the controls.

Till now few studies regarding the correlation of glucocorticoids level and acne have been done.

\section{CONCLUSIONS}

This study concluded that patients with severe acne, acne distributed along the jaw lines, recalcitrant acne not responding to conventional therapy and having other features of hyperandrogenism should be evaluated for the above-mentioned hormones to rule out the underlying hormonal abnormality leading to acne vulgaris.

\section{REFERENCES}

[1] Cordain L, Lindeberg S, Hurtad M, et al. Acne vulgaris: a disease of western civilization. Arch Dermatol 2002;138(12):1584-90.

[2] Pandey SS. Epidemiology of acne vulgaris. India J Dermatol 1983;28(3):109-10.

[3] Cunliffe WJ, Gould DJ. Prevalence of facial acne vulgaris in late adolescence and in adults. $\mathrm{Br}$ Med J 1979;1(6171):1109-10.

[4] Goulder V, Stables GI, Cunliffe WJ. Prevalence of facial acne in adults. J Am Acad Dermatol 1999;41(4):577-80.

[5] Kilkenny M, Merlin K, Plunkett A, et al. The prevalence of common skin conditions in Australian school students: III: Acne Vulgaris. Br J Dermatol 1998;139(5):840-5.

[6] Epstein E. Incidence of facial acne in adults. Dermatol Digest 1968;7:49-58.

[7] James WD. Clinical practice acne. N Engl J Med 2005;352(14):1463-72.

[8] Kligman AM. Postadolescent acne in women. Cutis 1991;48(1):75-7.

[9] Shaw JC, White LE. Persistent acne in adult women. Arch Dermatol 2001;137(9):1252-3.

[10] Cunliffe WJ, Cotterill JA, eds. Introduction. In: The acnes: Clinical features, pathogenesis \& treatment. Major Problems in Dermatology: Series 1: Vol. 66. London, WB Saunders Co., 1976:1-45

[11] Ghodsi ZS, Orawa H, Zouboulis CC. Prevalence, severity, and severity risk factors of acne in high school pupils: a community-based study. J Invest Dermatol 2009;129(9):2136-41.

[12] Cunliffe WJ. Natural history of acne. In: Marks L, ed. Acne and related disorders. London: Martin Dunitz 1989:4-6.

[13] Makrantonaki E, Ganceviciene R, Zouboulis C. An update on the role of the sebaceous gland in the pathogenesis of acne. Dermatoendocrinol 2011;3(1):41-9. 
[14] Addor FA, Schalka S. Acne in adult women: epidemiological, diagnostic and therapeutic aspects. An Bras Dermatol 2010;85(6):789-95.

[15] Thiboutot D. Hormones and acne: pathophysiology, clinical evaluation and therapies. Semin Cutan Med Surg 2001;20(3):144-53.

[16] Hay JB, Hodgins MB, Donnelly JB. Human skin androgen metabolism and preliminary evidence for its control by two forms of $17 \alpha$ - hydroxysteroid oxidoreductase. J Endocrinol 1982;93(3):403-13.

[17] Tutakne MA, Vaishampayan SS. Acne, Rosacea and Perioral Dermatitis. In: Valia RG, Valia AR, eds. IADVL textbook of dermatology. $3^{\text {rd }}$ edn. Indian Bhalani Publishing 2010:42-88.

[18] Vergou T, Mantzou F, Tseke P, et al. Association of thyroid autoimmunity with acne in adult women. J Eur Acad Dermatol Venereol 2012;26(4):413-6.

[19] Zaenglein AL, Graber EM, Thiboutot DM. Acne vulgaris and acneiform eruption. Fitzpatrick TB, Goldsmith LA,
Katz SI, Gilchrest BA, et al, eds. Fitzpatrick's dermatology in general medicine. Vol. 1. New York: McGraw-Hill Medical 2012: p. 897.

[20] Marynick SP, Chakmajian ZH, McCaffree DL, et al. Androgen excess in cystic acne. $\mathrm{N}$ Engl J Med 1983;308(17):981-6.

[21] Hatwal A, Singh SK, Agrawal JK, et al. Serum testosterone, DHEA-S and androstenedione levels in acne. Indian J Dermatol Venerol Leprol 1990;56(6):4279.

[22] Smith RN, Mann $\mathrm{Nj}$, Braue A, et al. The effect of highprotien, low glycemic-load diet versus a conventional, high glycemic-load diet on biochemical parameters associated with acne vulgaris: a randomized, investigator-masked, controlled trial. J Am Acad Dermatol 2007;57(2):247-56.

[23] Shome B, Schiller M, Saffaran M. Peptides of the hypothalamus. J Neurochem 1966;13(5):433-48. 